\title{
CALL by design: discourse, products and processes
}

\author{
MIKE LEVY \\ Griffith University, Queensland, Australia \\ (email: michael.levy@mailbox.gu.edu.au)
}

\begin{abstract}
'Design' is a term that is familiar to many language teachers and CALL practitioners. It is used regularly in relation to curriculum, syllabus, course and task in the general literature and it occurs in all these areas and more in the CALL sphere where instructional design, website design, interface design and screen design are just some of the additional points of focus. This paper aims to look at CALL design in more detail. It places a particular emphasis on describing the discourse, products and processes of design in CALL. It looks at what we have learnt about design and points to areas that remain problematical. It also makes connections with cognate fields whenever these links prove helpful. This study is the second in a series of three complementary papers which look at research, design and evaluation in CALL (see Levy, 2000). All use the same corpus of CALL work as a database and the research design and methodology in each is the same. In this paper the description and discussion is based on 93 articles involving design published in books and journals published in 1999. The descriptive section is followed by analysis and interpretation with special attention given to the relationship between theory and design, and the centrality of the task and the learner in the design process.
\end{abstract}

\section{Introduction}

A cursory glance at the literature shows that the idea of design, in one or another of its aspects, is a recurring theme in CALL. Yet design is a rather amorphous idea at best, and it is rather difficult to know quite where to begin when discussing it. In the CALL literature it crops up in many forms. Examples from the 1999 corpus include: design philosophy (Nelson \& Oliver, 1999); design and production (Fischer \& Farris, 1999); curriculum design (Levine, Ferenz \& Reves, 1999); syllabus design (Klassen \& Milton, 1999); course design (Koet, 1999); materials design (Chen, 1999); task design (Mills, 1999); exercise design (Arneil \& Holmes, 1999); interface design (Brussino, 1999); and screen design (Jones \& Frommer, 1999). Initially, then, we can say that the discourse on design and CALL functions at many levels.

The products of CALL design provide another window on design. In the corpus there was considerable variety in focus and scope. Examples range from Sivert and 
Egbert (1999), who describe the building of a computer-enhanced language classroom, to Harben (1999), who considers in detail the design of a specific CALL exercise. There are numerous examples in between and include CALL design issues in relation to websites (Mugane, 1999), learning environments (Goodfellow, Manning and Lamy, 1999), authoring systems (Frommer \& Foelsche, 1999) and 'named' CALL projects (Brussino, Luciano \& Gunn, 1999).

This range of products reflects the many goals and orientations of CALL designers. This point is reinforced when the points of departure for projects is considered. A small sample from the CALL-1999 corpus is illustrative:

- Bernstein et al. (1999:361): "Subarashii is an experimental computer-based interactive spoken language education (ISLE) system designed to understand what a student is saying in Japanese and to respond in a meaningful way in spoken Japanese."

- Brussino et al. (1999:410): "The Crescendo in Italia multimedia CDs were designed to meet the needs of the intermediate Italian programme at the University of Auckland."

- Fischer \& Farris (1999:59): "The Libra authoring environment was designed to enable faculty to create multimedia materials that focus on facilitating students' acquisition of listening comprehension proficiency in foreign languages." (p. 59)

- $\quad$ Pusack (1999:26): "Given these tendencies, my concept for the design of foreign language instructional software derives from the need to achieve an optimal mix between in-class and out-of-class learning."

- Wong \& Fauverge (1999:135): "The aim was to engineer a situation which would require students to engage in a series of meta-conscious processes including planning, monitoring and negotiation of meaning." [My italics]

Each example illustrates the centrality of design in the initial conceptualisation of a CALL project or task and the very important point that CALL design is heavily context dependent. In other words, designers are often concerned primarily with meeting local needs, typically related to their own learners and curriculum.

From this brief and preliminary snapshot of CALL design, it is already clear that design is a multi-faceted phenomenon and that language teacher-designers talk about their work at a number of levels and with a variety of focal points. Consequently, there are many ways that one might approach a discussion of this topic. This paper proceeds in the following way:

First, it looks at design as it was represented in the literature in CALL in 1999. 177 items were published in that year, more than twice as many as in the following year using the same selection criteria. ${ }^{1}$ As such this represents a large and recent body of CALL work. The CALL-1999 corpus included, with a small number of exceptions, all the chapters in four books (Cameron, 1999a, 1999b; Debski \& Levy, 1999; Egbert \& HansonSmith, 1999) and all the articles in four major CALL journals, Computer Assisted Language Learning, CALICO, ReCALL and Language Learning and Technology.

Second, it uses a specially designed thesaurus of identifiers and descriptors (see Levy, 2000). The identifiers and descriptors spanned all aspects of language teaching, learning and technology pertaining to CALL research, design, development, evaluation and prac- 
tice. The additional terms referred to in this paper are given in Appendix A.

The paper begins with a section showing in very broad terms some frequency counts featuring 'Design'. This is followed by a more detailed descriptive section which deals in turn with design as a principled approach to CALL and artifact design. Artifact design includes discussions of design for websites and learning environments, courseware projects, online courses, state-of-the-art technologies and authoring systems. This is followed by discussion, analysis and interpretation. This section concentrates especially on the relationship between theory and design, and the role of the 'task' construct and the learner in the design process.

Finally, note that there is insufficient space here to do full justice to the design perspectives and CALL programs presented by individual authors. Only a brief overview will be possible because of the limits of space and the breadth of the discussion. The reader should refer to the original publication cited in this paper for a more complete understanding of the author's position.

\section{Description}

\subsection{A quantitative overview}

In the CALL-1999 corpus of 177 journal articles and book chapters, there were 93 $(52.5 \%)$ items that considered design in a significant way. The identifier 'Design' is defined in detail in Appendix A. The term was used in the following ways:

- design as a principled approach to CALL, including approaches to the design of CALL tasks

- design of an artifact

- design of CALL materials sharing a 'state-of-the-art' technological feature

- design of an online course

- design as it relates to other aspects of CALL.

Members of the first group describe a 'paradigm', 'theory', 'model' or 'methodology' as a starting point for CALL design (e.g. Hoven, 1999a; Hémard, 1999). They each provide a vision or conceptualisation of design as it relates to CALL. These perspectives consider such aspects as language learning theory and design, task design, software design, learner-centred design and issues relating to the special attributes of multimedia. Sometimes these elements are considered in combination to form a model or design framework. Though different, each viewpoint or perspective is fully articulated and internally consistent, and it is comprehensive within its own parameters.

Artifact design included the building of websites, learning environments, courseware packages, exercises and authoring systems. State-of-the-art technologies included systems utilising automatic speech recognition, and broadband, multicast video-conferencing. Other aspects included discussions of design and computer or classroom laboratories, Intelligent CALL (ICALL) systems, corpus-based work and the design of grammar-checkers.

Figure 1 shows the identifier 'Design' alongside the other most frequent identifiers in the CALL-1999 corpus. All identifiers are defined in Appendix A apart from those 
defined in the earlier paper (Levy, 2000). The 47 'Research' items shown in the figure were the object of discussion in the first paper in this series (see Levy, 2000). 'Evaluation', which is also clearly a point of discussion for CALL researchers and practitioners, is to be the topic of a third paper. From these figures, design and evaluation are the two most frequent identifiers in the corpus. ${ }^{2}$

Figure 2 shows the most frequent CALL identifiers that co-occur with 'Design'. Aside from research and evaluation, which are covered elsewhere, the remaining identifiers have been used as a guide for the description, analysis and discussion presented in this paper. Design as a principled approach to CALL will be discussed first and examples will be given of how principle, theory and task relate to the design process. This will be followed by an examination of the different kinds of CALL artifact. Representative examples will be drawn from the corpus including authoring systems, represented by the identifier 'Authoring', and state-of-the-art technology, represented by the identifier 'Technology'.

\subsection{Design as a principled approach to CALL}

The members of this group consider design more generally and at a higher level of abstraction than those who discuss design in more specific ways related to an artifact (see Appendix A). Included in this category are guidelines or software design principles (Boling \& Soo, 1999; Peterson, 1999), broad approaches to design conceptualisation (Borchardt, 1999; Levy, 1999), a model of CALL design (Hoven, 1999a, 1999b; OrsiniJones, 1999) and a user-centred methodology (Hémard, 1999). In the synopsis here,

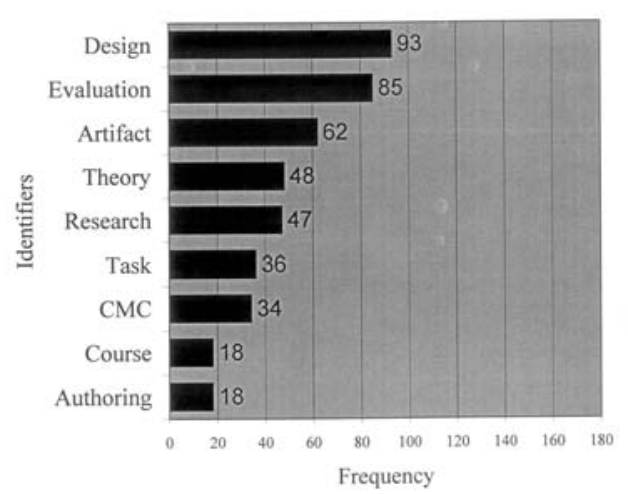

Fig. 1. The most frequent CALL identifiers $(n=177)$.

\footnotetext{
${ }^{2}$ At the EuroCALL Conference 2001, in Nijmegan, seven themes were used to classify conference papers. The first theme was 'Design of software for interactive language learning'; the second theme was 'Assessment of the effectiveness of Computer-Assisted and Web-Enhanced Language Learning'. As an informal, comparative and independent measure, it is noteworthy that the first theme was assigned 43 times $(43 / 114=49.0 \%)$ and the second theme was allocated 39 times $(39 / 114=44.1 \%)$ showing a strong correlation with the equivalent frequencies for 'Design' and 'Evaluation' in the CALL-1999 corpus. This point is for noting only.
} 
Hoven's two papers exemplify a CALL model with a focus on task design, and Hémard's two works illustrate a user-centred methodological approach to design.

Hoven (1999a, 1999b) describes a learner-centred design model in terms of a sociocultural language learning methodology. Five principles for a CALL model are proposed incorporating sociocultural methodology, learner centredness, control and student awareness-raising, task-based pedagogy and models of good practice. The various elements combine and inter-relate to form the model. A key element of the model is the 'sociocultural paradigm' for CALL (Hoven 1999b:151). Hoven's discussion is consistent with the well-established tenets of this orientation on language learning (e.g. see Mitchell and Myles, 1998, Chapter 7). Following Vygotsky's work, it emphasises the importance of mediated learning and scaffolding and the idea of the Zone of Proximal Development (ZDP). ${ }^{3}$

In this orientation there is a strong emphasis on selecting an appropriate task design for CALL activity. Hoven speaks of a 'task-based pedagogy' and provides a desired feature list for optimal CALL tasks. In a similar vein, in her paper on computers as tools for collaborative language learning, Meskill (1999:145) provides a 'task anatomy' where "...task features align with active, participatory, meaning-centred tasks that language instructors strive to design and orchestrate." The focus on task design in this orientation is important and represents one of the major ways in which the transition is made from a theoretical position to actual CALL practice. In other words the theory is realised in practice through a specific type of task design.

In contrast, Hémard (1999) and Hémard \& Cushion (1999) provide another perspective on CALL and design. A theoretical orientation is still included though it is less central and not theory-driven: Hémard \& Cushion (1999:173) speak of "a balancing act between theory and practice...". They also place a very strong emphasis on learner perceptions in a way that is rather different from that described above. For Hémard (1999:215), the goals of basic CALL research and design have focussed too heavily on discovering how best students learn a language and thereby the design of learning tasks. He believes it is time to make a readjustment and focus much more on the learner. In his view, we need to focus on learner goals and their perceptions of the quality of the CALL user interface, and thereby to reach a much more detailed and specific understanding of students' views and preferences. Specifically, Hémard's methodology proposes, “...a contextualised approach and Human-Computer Interaction (HCI) techniques, designed to involve students and provide them with the necessary context and support to generate valuable feedback and clearly enunciated requirements" (1999:217).

A special emphasis on learner perceptions of CALL activities and the way a learner experiences their own learning is evident also in Goodfellow (1999:110) who says, "By engaging with the phenomenological idea that the learner's perception of the program and their experience of the interaction are not simply factors affecting the outcome, but actually constitute the outcome, we can put a more fundamentally humanistic principle at the centre of the design process."

Other members in this category take different approaches. Two authors provide a set

\footnotetext{
${ }^{3}$ The Zone of Proximal development is defined as "...the domain of knowledge or skill where the learner is not yet capable of independent functioning, but can achieve the desired outcome given relevant scaffolded help." (Mitchell \& Myles, 1998:146).
} 
of design guidelines, an approach to the articulation of design that has been frequent during the short history of CALL (see Hémard, 1999; Levy, 1999b). Thus, Boling and Soo (1999) provide guidelines for well-designed software with autonomy issues and the distribution of control between the teacher, the student and the computer the central themes. Peterson (1999) proposed a set of guidelines for designing hypermedia learning environments with a framework drawing upon cognitive science, ESL pedagogy, instructional design, HCI and SLA.

Levy (1999) looks at how the 'design space' is mapped out initially and looks at three principal distinctions at the outset; holistic and discrete element approaches (e.g. a program focusing on a level of linguistic description, such as pronunciation or lexis); tutor and tool roles for the computer; and theory-testing programs for research purposes as opposed to application projects meant for everyday use in the classroom. He emphasizes the importance of levels of conceptualisation in design that help link the more abstract, theoretical level with the practicalities of building an actual program. In this the theorydesign link is carefully examined.

Some authors situate CALL design within the larger context of computer technology and design more generally. For example, Borchardt (1999) develops ideas on multimedia design through consideration of the history of design and aesthetics. He notes how certain design practices can be ascribed to, "...the taste of the time or the taste of the designer or the user, and...to the internal dynamics of the medium..." (1999:27). A good example is the remarkable conformity of contemporary screen design. To a considerable degree then notions of 'good' and 'bad' design are the result of the 'tastes' of the moment. They cannot be ignored because students bring these ideas about design to their CALL work, and such perceptions contribute greatly when students are asked to comment on the quality of CALL activities and programs.

\subsection{Artifact design}

As may be seen in Figure 2, the identifiers 'Artifact' and 'Design' regularly co-occur. This section addresses design issues in relation to the nature of the artifact involved. Included are websites and learning environments, courseware projects, online courses, state-of-the-art technologies and authoring systems. Generally, two representative examples will be given in each case.

\subsubsection{Websites and learning environments}

The two artifacts described in this section provide examples of a website and a learning environment. The first example is the Stanford African Languages and Multimedia Applications (SALAMA) site (Mugane, 1999); and the second is the 'Virtual Language Centre' (Greaves \& Yang, 1999).

Mugane used the metaphor of the 'arena' and an 'access-to-resources' model to characterise the community activities that were possible via the SALAMA website. The specific goals in this project were to develop communicative competence and cultural awareness in Swahili (Mugane, 1999: 34). He described in detail the structure of the website and the ways in which learners might engage with it, both individually and collaboratively. Free and guided browsing options were a special feature of the design. The 




Fig. 2. The most frequent CALL identifiers co-occuring with 'Design' $(n=93)$.

'topics' included 'grammar', a 'dictionary', 'movie-clips', 'issues' and 'exercises' and they fall into three groups: "a gateway to cultural content; grammar and vocabulary portals; and exercises and quizzes" (Mugane, 1999: 37). Notable also was the strong and continuing involvement of students in the construction of the SALAMA site.

The 'Virtual Language Centre' (VLC) was similarly a website with multiple resources. The 'fundamental principle' underpinning its design was "the integration of vocabulary, lexicon, concordancing and multimedia on a unified platform." (Greaves \& Yang, 1999: 83). They state that the VLC has two levels of functionality: "1. The provision of a range of language study materials, reference sources, exercises and so on for users who may be students or teachers; and 2. the processing of information, requests and messages received from users and the provision of feedback to the users." (Greaves \& Yang, 1999: 71).

SALAMA and the VLC are each good examples of integrated CALL learning environments. They each involve a coordinated and suitably linked collection of resources plus a mixture of tools and tutorial features that, properly managed, can provide learners with the information and help they need when they need it.

\subsubsection{Courseware projects}

The first example in this section is taken from a special issue of the CALICO journal on the "practice of courseware design and production" (Jones, 1999a: 5). In this issue the emphasis was on the process of CALL materials creation and in their papers authors were initially asked to consider, "the developer's underlying philosophy, the context of the project, content and technical constraints, a narrative description of the production process, and lessons learned by the project's end." (Jones, 1999a: 6).

Blake described the design and development of the Nuevos Destinos CD for intensive or advanced beginners of Spanish. It was designed around a narrative plot involving real-world problems and tasks in a virtual law office. The article tracked the progress of the project from initial concept to final production and testing. The theoretical orientation drew on the interactionist approach, a widely recognised theory of SLA (see Ellis, 1994:243-244, 709). Interaction, meaningful tasks, negotiation of meaning and 
collaboration are paramount. In this case, as learners will be interacting with a computer program, Blake (1999:11) says, "The basic theoretical question...is whether or not a CD-ROM program...can successfully promote L2 learning....although no other interactant is present." The question of what 'interaction' actually means in this context is discussed in some detail.

The ensuing discussion covered the composition of the project team which included a content expert, interface and graphic designers and programmers. The creative value in design of having a team composition where members could offer contributions from different perspectives was emphasised. The discussion went on to describe the storyline of the video component, the design of the interface and the specification of all the tasks, activities and exercises. The stages in the development were covered as was the role of team members at the different stages of the development process. As with all contributions to this special issue, the immense value of involving students at points through the design and development process was emphasised.

In fact the concluding sections in each of the contributions to this collection were most informative as designers and developers reflected on their experience. A concluding comment by Nelson \& Oliver (1999) is worth quoting at some length:

It is not possible to design an effective project a priori; usability testing is a must. Formal and informal evaluative processes are integral to creating good learning environments. Pedagogy should determine the technology, and users should be given a voice in the process. Often instructors impose a pedagogy (or technology) without asking for students' opinions. If, instead, students' comments, ideas and preferences are brought into the development process, the final product is not merely determined by need; students will want to use it. (Nelson \& Oliver, 1999:112)

\subsubsection{Online courses}

In the CALL-1999 corpus, $10.2 \%$ of entries (18/177) represented examples of courses either wholly presented via technology, or partially presented that way. Also, when course provision was multi-modal, a combination of face-to-face teaching and webbased work, the question of integration of the various elements was frequently discussed. Crompton's contribution, “Integrating Internet-based CALL materials into mainstream language teaching" is considered here because of the ways in which the author made adjustments and refinements to the design of the online version through successive iterations of the course.

In Crompton's case the starting point for an online version of the course was an existing course implemented without technology. This course was a complete grammar course for Spanish from beginners to post- 'A' level. The original, 'hard copy' version included grammar explanations, grammar exercises, and a student self-checking component. As well as the completed grammar work, students had to hand in a Student Progress Log. The hard copy version was tried and tested, and for a variety of reasons economy, flexibility and access-related primarily - the decision was made to proceed with an online version. Version I of the online version replicated the design of the original offline version in many ways, and it was only through the transition to Mark II that 
real substantive changes were implemented in the design of the course. The changes that occurred and how they came about are considered in the discussion section of this paper (see Section 3.5).

\subsubsection{State-of-the-art technologies}

Programs or learning systems in this group share a recent technological innovation or feature. While the labels 'state-of-the-art', 'new' or 'recent' are, of course, very relative terms, at any point in time there are technologies which are only beginning to make their way in the CALL domain. These innovative technologies have not yet reached critical mass nor widespread use and acceptance by the CALL community at large. Currently, these technologies are held to include automatic speech recognition and broadband multicast videoconferencing.

Automatic Speech Recognition (ASR) was the technology binding the contributions in another special issue of the CALICO Journal in 1999 entitled, 'Tutors that Listen' (Holland, 1999). Ten contributions plus an introduction looked at the design of some well-known and some lesser known speech recognisers in the context of the design of CALL systems. These projects included programs designed to provide virtual dialogues with native speakers (e.g. Harless, Zier \& Duncan, 1999), reading tutors (e.g. Mostow \& Aist, 1999) and pronunciation training programs (e.g. Dalby \& Kewley-Port, 1999). Wachowicz \& Scott (1999), in their review, say three aspects of speaking were being addressed using ASR: vocabulary development, conversation skills practice and pronunciation (1999:255).

In Project LISTEN, Mostow and Aist (1999:407) examined how the advantages and disadvantages of speech recognition technology helped 'shape the design and implementation' of a reading tutor. They discussed key problems in children's reading such as word identification, 'attentional bottlenecks' and motivation, and, in the light of this, and well-defined pedagogical goals, they described the strengths and limitations of their ASR system, the Sphinx-II continuous speech recognition system. The Project's reading tutor used ASR to 'listen' to the students as they read aloud, and it then gave feedback using an intervention model designed by the authors. The strengths and weaknesses of the ASR component very much shape the design as was clear when the authors stated very succinctly: "Using automatic speech recognition means never being able to say you're certain." (Mostow \& Aist, 1999:419). This later point was echoed in the detailed overview by Wachowicz and Scott when they said that state-of-the-art speech recognition is never 100\% accurate, regardless of the ASR engine used (1999:254). They caution against making claims about ASR engines that reach well beyond their actual capabilities. With this in mind they made two important points: "Our review suggests that the effectiveness of speech-interactive CALL is determined less by the capabilities of the speech recogniser than by (a) the design of the language learning activity and feedback, and (b) the inclusion of repair strategies to safeguard against recogniser error" (Wachowicz \& Scott, 1999:253).

The other noticeable area of growth in a state-of-the-art technology in 1999 was broadband, multicast videoconferencing (e.g. Buckett, Stringer \& Datta, 1999; Wong \& Fauverge, 1999). Both these projects were designed for highly interactive, small group tutorial teaching (4-6 students) with participants working on 'a common task' that 
required collaboration from all group members.

Wong \& Fauverge (1999:133) reported on the LEVERAGE project which involved "the experimental use of a broadband computer network hypermedia environment for language learning (French, English, Spanish)". Using Web-based resources, students engaged in a collaborative task over a network which offered high quality video-conferencing, application sharing and access to authentic multimedia resources. As on many other occasions in this review of design in CALL, Wong and Fauverge described a 'task-based pedagogy' as a key component of the design. A specific question in this study looked at how effectively a 'task-based approach' was suited to this kind of networked environment. Here, given the capabilities of the technology, they looked closely at the 'practicalities' of 'reciprocal peer tutoring'. In this case learners of one language were grouped with learners of their native language and so, for example, two Englishspeaking students were paired with two French-speaking students and worked together on a common task. In this CALL environment the various roles taken by the participants - as language 'experts', or as language 'learners' - at different points through the process of task completion were examined closely.

\subsubsection{Authoring systems}

In the 1999 CALL literature, three authoring systems were discussed in considerable detail: 'Hot Potatoes' (Arneil \& Holmes, 1999); 'SuperMacLang' (Frommer \& Foelsche, 1999); and 'Libra' (Fischer and Farris, 1999). In each case the history, design philosophy, activity types and key stages in the development of the system were discussed. Here we will focus on the development of the 'Hot Potatoes' web authoring tool. In their paper, Arneil and Holmes addressed design issues relating to "exercise design, the ability to customise and control the output for different browser versions, user-interface design, ancillary technology and technical support" (1999:12).

In much of their discussion, as reflected in the title of their paper, Arneil and Holmes consider the ways in which the technological infrastructure available variously forms and shapes the design decisions. Notable here are specific browser requirements forcing certain choices. Extensive end-user testing is necessary because of the differences between browsers and subsequent versions of the same browser. Again in exercise design they talk about the limitations of the medium and the need for materials designers to work with them, and they also discuss the balance required between flexibility and practicality. They also design for novice and sophisticated users, a consideration that leads to several levels of configuration to enable users to operate at the skill level desired. Arneil and Holmes conclude: "This complex mix of decisions and balancing acts underlies the design of all authoring tools..." (1999:18).

Aside from authoring and the items already mentioned, there were a number of other examples in the CALL-1999 corpus that involved design in a significant way; unfortunately, space only allows a passing mention here. They included design as it related to: ICALL (seven items including Hamburger, Schoelles \& Reeder, 1999); corpus-based CALL and concordancing (6 items including Whistle, 1999); grammar checkers (2 items including Tschichold, 1999); and the computer classroom or laboratory (Sivert \& Egbert, 1999). Each of these items has descriptors assigned to them in the CALL-1999 corpus. It should be remembered that the literature in this study only looks at the year 
1999 and in the light of the categories listed above, perhaps especially with regard to corpus-based CALL, this represents a limitation of the study.

In the descriptive overviews given so far, a number of themes seem to rise to the surface again and again. These include the role of theory in design, the centrality of the task construct as a means of operationalising a theory and translating it into practice, the need for trade-offs or compromises in design to reconcile teaching/learning goals with technological constraints, and the value of having students closely involved in the design process. These themes are now explored in more detail drawing on cognate fields and disciplines where helpful.

\section{Discussion}

\subsection{Theory and design: philosophical perspectives}

While an in-depth discussion of the philosophical bases of CALL is well beyond the goals and scope of this article, there are deeper philosophical issues that can shed light on a number of important contemporary design issues in CALL. The relationship between theory and design is a good example. Can our designs be theory-driven and, if they can be, should they be? What are the implications for the designers and the users? In order to pursue such questions two philosophical positions, the rationalist and pragmatist, will be described briefly. The arguments presented here follow a much more detailed and comprehensive account in an influential work on the philosophy of design in a technological context by Richard Coyne (1997).

\subsubsection{Rationalism}

Rationalism is any philosophy that emphasises the primacy of pure reason. It gives priority to reason over other means of knowledge acquisition and justification such as that gained through experience and the senses (Blackburn, 1994). Coyne (1997) says rationalism is a philosophical position we are all involved with as far as our understanding of technology and of design is concerned.

In the rationalist tradition, theory is the principal concern and is held to be superior to practice. Thus, the theoretical leads and directs the practical and, generally speaking, practical concerns are of a very limited interest within this orientation. Coyne (1997:27) provides a useful summary:

It is assumed that practical implementation eventually follows from sound theory. Rationalism does not promote concern about immediate practical outcome. In summary, rationalism supports the view that technology is a product of theoretical inquiry and is subservient to it. This is a further instance of the widely held view that technology follows scientific development - technology is applied science.

In contemporary society, rationalism is very much the dominant view. Winograd \& Flores (1986:16) add:

...the rationalistic orientation pervades not only artificial intelligence and the rest of computer science, but also much of linguistics, management theory, and cognitive science... rationalistic styles of discourse and thinking have determined the ques- 
tions that have been asked and the theories, methodologies, and assumptions that have been adopted.

This philosophical position has been and still is very influential in CALL research and design practice. What constitutes 'good' research is still often defined within these parameters.

In CALL, the influence of rationalism has been keenly evident in the literature, most notably in arguments that favour theory-driven design practice and formulaic, linear approaches to design that insist upon distinct, sequential stages during the design process (see Levy, 1997, 1999a, 1999b; Coyne, 1997:21, 22).

\subsubsection{Pragmatism}

Pragmatism is a philosophical school of thought that contrasts starkly with rationalism. For pragmatism, Coyne (1997:31) asserts:

This orientation is primarily concerned with what works - actions and consequences. In other words it begins with an understanding of technologies in the human context - how the technology fits within the day-to-day practical activity of people. A concern with theory (in the sense of generalisations, rules and formulas) is therefore displaced by practice.

The relative status of theory and practice, which dominates, and which is held subordinate, characterise one of the key differences between the rationalist and pragmatic traditions in philosophy. For the pragmatist, theory-making is a kind of practice, the two are intertwined, or in the words of Hickman (1992:99), "Theory no longer had to do with final certainty but instead, as working hypothesis, with the tentative and unresolved." Pragmatists are highly critical of the idea of practice as theory-driven. In presenting the position of the pragmatists, Coyne (1997:11) says that "For pragmatism, design is a kind of 'reflection in action' - needs are commonly identified in retrospect or during development...rather than at the outset." He continues (1997:48, 49):

In some quarters, the language of practice is considered to lack the sophistication of 'theory talk.' So people revert readily to 'theory talk' to justify their practices. We pay lip service to the importance of theory, while our research or design betrays our commitment to practice. This quiet victory of pragmatism is evident in the 'pragmatic turn' taken in design methods.

In terms of design then, instead of theory dictating design from the outset which then proceeds in a linear fashion, for the pragmatist the design process is more a question of reflecting on goals and constraints iteratively in a cyclical design process.

Another important characteristic of the pragmatic orientation concerns the way in which the technology aspect is considered to be a kind of envelope that surrounds and permeates the ways in which we think about it: "Technological thinking 'enframes' us into particular ways of thinking." (Coyne, 1997:9); and "We are shaped by our technologies as much as we fashion them" (Coyne, 1997:7). In contrast with the rationalists then - where 
'technology follows science' and is seen as an application of a theory or pre-set plan with the pragmatists, technology permeates our thinking and our design conceptualisations from the outset.

For CALL, Goodfellow (1999) reflects a pragmatic orientation when he describes a number of reservations about using a theory or a 'psycholinguistic model' as a point of departure for design (pp. 114-117); he says, "...the designer has to make a choice between theoretical validity and practical effectiveness" (p. 118). He continues: "Whilst a design may be based on psychological principles that are a priori, its educational effectiveness is often a more empirical matter, decidable only through an iterative process of development and evaluation, with attention being paid at all times to the context of learning and the learner's experience of it." This is a point that is made again and again in the CALL literature when designing for real educational settings, notably in many of the contributions to the CALICO Special Issue on courseware design (Jones, 1999a), and also in the design and development work of Holland, Kaplan \& Sams (1995), Hémard (1999) and Arneil \& Holmes (1999).

A pragmatic orientation is also evident when the idea of metaphor is employed as a design technique; Coyne argues that metaphor as a focus in design discussion belongs very much in the pragmatic domain (Coyne, 1997:13). Metaphors used for projects in the CALL-1999 and 2000 corpora included:

$\begin{array}{ll}\text { A personal journey } & \text { (Brussino, 1999) } \\ \text { An arena } & \text { (Mugane, 1999) } \\ \text { A murder mystery } & \text { (Nelson \& Oliver, 1999) } \\ \text { A workroom, bookcase } & \text { (Shield \& Weininger, 1999) } \\ \text { A toolbox } & \text { (Vanparys \& Baten, 1999) } \\ \text { A conversational partner } & \text { (Price } \text { et al., 1999) } \\ \text { A bag or pack } & \text { (Chun \& Plass, 2000) } \\ \text { A conference } & \text { (Debski, 2000) } \\ \text { A community } & \text { (Lam, 2000) }\end{array}$

Also, language learning websites such as Dave's ESL Café, the VCU Trail Guide, the CALL CookBook and the Grammar Safari are well-known and in some cases very successful. Although the value of metaphor in design should not be overstated, some of the benefits of using metaphor in CALL design are evident in the help such a tactic provides for:

- CALL designers, teachers and students in conceptualising a new program, website or language learning environment at the outset;

- students in imagining the language learning experience before they actually encounter it (e.g. level of formality);

- students in appreciating the role of the online course component in relation to offline or classwork elements;

- students in understanding the role and pervasiveness of the culture in the language and for raising cultural awareness.

Using metaphor in design also illustrates very powerfully that when designing for real educational settings, the designer is creating learning environments not decontextualised 
learning interactions. The different goals of the designer lead to different roles for theory, and this issue is discussed in the next section.

\subsection{Linking theory and design: project goals}

It is easy to make the assumption that if a theory is well-proven and accepted, clearly articulated designs will automatically follow in a clear and unambiguous way. This is not the case. Ohlsson (1993) observes that theory cannot uniquely specify a design: design is not a deductive consequence of a theory (see also Holland et al., 1995:xi; Boyle, 1997:80, 85).

Ohlsson goes on to provide a useful analogy in the design of the aeroplane (1993: 198). If the aeroplane is to fly, of course it cannot violate the laws of physics. However, the laws of physics do not dictate how the aeroplane is to be built. The physical laws do not prescribe the perfect design, but a "space of workable designs" (p. 198). The design selected will be chosen for reasons other than specified by the physical laws, based upon factors such as purpose, capacity, speed, fuel consumption, cost and so on. So although theory provides a crucial baseline, it is not of itself sufficient to determine the design many other factors come into play. If a theory cannot determine a design, how then might theory be linked to design in a way that is meaningful at a practical level?

Jacobson (1994) provides a valuable framework for linking theory to design in the context of hypermedia design in real educational settings. He describes a Theory-ToDesign framework that has two central precepts. The first argues that there are two main roles for theory in design, which Jacobson calls theory construction and testing and prescriptive artifact design.

In theory construction and testing, the theory operates within the quantitative model of scientific research. Here carefully controlled experimental studies are employed, and specific theoretical elements are manipulated to test the theory. The design features that are built into the system are a 'means to an end', and are used to confirm or reject the theory. A succession of such studies helps modify or refine the researcher's theoretical understanding of the problem.

In contrast, in prescriptive artifact design the primary focus is on developing a system for use in a real educational setting. Such studies are usually non-experimental, and design features may be drawn from one or more theoretical perspectives. In theory construction and testing, the theoretical position is purposefully made explicit, whereas in prescriptive artifact design theoretical elements may remain implicit and in the background (Jacobson, 1994:143). In prescriptive artifact design Jacobson says, "The instructional artifact becomes an end in itself that serves a particular purpose in a social context (e.g. promote student learning) rather than being an explicit means to test or refine theoretical constructs." (1994:143).

In both theory construction and testing and prescriptive artifact design there is a direct relationship between theory and design. However, in the former, one specific theory is normally tested whereas in the latter, one or more theories may be utilised, a characteristic Jacobson describes as theoretical pluralism. In prescriptive artifact design, multiple theories which operate in a 'complementary and synergistic' fashion are used to underpin different aspects of the design.

It is important to appreciate the need for theoretical pluralism in prescriptive artifact design. In this regard, Boyle notes that presentation design has its own problem space, 
that it is quite different from conceptual design, and requires its own theories and rationale (Boyle, 1997: 2, 121). Different facets of a fully realised CALL program draw on a number of complementary theoretical bases. This view is also compatible with ideas about the value of teamwork in design, put forward by Blake earlier in Section 2.3.2.

\subsection{SLA as a source of theory}

If the idea of theory-driven design is accepted, then the most obvious source of theory is the field of Second Language Acquisition (SLA) since it is directly concerned with language learning.

A theoretical position on language learning, of course, requires a view on the nature of language and a view on the nature of learning. Researchers in the fields of linguistics and SLA are precise about how they define language and, consequently, how they approach, characterise and measure language learning. In the recent Mitchell and Myles's (1998) review, they include the following approaches to second language learning: the Universal Grammar (UG) approach; cognitive approaches; functional/pragmatic perspectives; sociocultural perspectives; and sociolinguistic perspectives. Inasmuch as each of these frameworks represent an agreed position, each perspective or approach holds to a particular view of language and a particular view of learning. Were a designer to draw on SLA for a theoretical point of departure, the designer would need to be able to evaluate these various positions and adopt the most appropriate for the context.

For CALL, the sociocultural perspective on language learning has been referred to frequently (see Section 2.2), and Mitchell \& Myles provide an evaluation (1998: 160-2). As far as language is concerned, Mitchell and Myles say that "sociocultural theorists do not offer any very thorough or detailed view of the nature of language as a formal system." (p. 161) and "they have typically dealt in fragments of language, often isolated elements of morphology, the conventional focus of form-focussed instruction,...” (p. 161). As far as learning is concerned, they apply a general learning theory to language learning, using such concepts as 'private speech', 'activity theory' and 'scaffolding', largely following the work of Vygotsky. This general learning theory, which has been very influential in other domains of social and educational research, is then applied to language learning (p. 160). Like the cognitivists, sociocultural theorists assume some general learning mechanisms will apply to language learning, whereas those who adhere to the Universal Grammar (UG) approach, for example, would argue that language learning is a very distinctive form of learning. UG also advances a sophisticated and highly specified position on the nature of language.

Viewed as a whole, as a field of academic endeavour, SLA research has primarily concentrated on explaining the acquisition of morphosyntax and somewhat neglected the acquisition of phonology, the lexicon and pragmatics (Larsen-Freeman \& Long, 1991: xiv). Larsen-Freeman and Long depict the collective position of the SLA field as follows:

...the view of language acquisition as a product of rule formation (or in its latest guise, parameter setting...) has still prevailed. This is probably due to the fact that SLA research attention has continued to focus on morphosyntax, which presumably 
can be best accounted for through such a process. As SLA stretches to consider other aspects of linguistic and communicative competence, however, it would not be surprising to see that other types of learning will have to be considered. For example, we may yet find that habit formation has an explanatory role in the acquisition of L2 phonological features and in the acquisition of formulaic utterances as well (p. 73).

Though written a decade ago, it is fair to say that the field of SLA, and the sub-fields within it, view language and learning in very specific ways. Generally, theories are considerable applicable in strictly limited domains. No single theoretical position has achieved dominance and new theoretical positions are continuing to appear (Mitchell and Myles 1998:x). This is perhaps to be expected in a field that is dealing with something as complex as language learning.

For the CALL designer who is not an expert in SLA, but who is nevertheless seeking a sound theoretical foundation from that domain, these various views and perspectives from SLA research can present a significant problem, one that is not dissimilar to the difficulties encountered in applying the results of SLA research to language teaching. Both the strengths and weaknesses involved in the applications of SLA research are summarised concisely by Mitchell \& Myles (1998) citing the work of Ellis (1997): "The findings of SLA research are not sufficiently secure, clear and uncontested, across broad enough domains, to provide straightforward prescriptive guidance for the teacher (nor, perhaps, will they ever be so)" (Mitchell \& Myles, 1998: 195). Even for the subfield of instructed SLA, they continue "instructed SLA research is not identical with problemsolving and development in language pedagogy, and does not ensure a shared agenda between teachers and researchers." On the other hand, Mitchell and Myles add that we should certainly not forget the value of this association: “...present SLA research offers a rich variety of concepts and descriptive accounts, which can help teachers interpret and make better sense of their own classroom experiences, and significantly broaden the range of pedagogic choices open to them." (Mitchell \& Myles, 1998: 195). The same points, I believe, apply in CALL.

\subsection{Focus on the task}

It was evident in the earlier descriptive sections that the task construct was frequently referred to as a means of converting a language teaching approach, or a theory of language learning, into a practical activity for students to complete. The task is often held to embody the fundamental principles of the design. In CALL, in addition to those already mentioned, there are many papers in the 1999 corpus that refer to task frameworks or task features that aim to encapsulate an underlying pedagogical rationale or learning theory (e. g. Chapelle, 1999; Mills, J., 1999; Shield, Weininger \& Davies, 1999).

In language teaching in the mid to late 1980s, publications such as 'Language Learning Tasks' (Candlin \& Murphy, 1987) and 'Designing Tasks for the Communicative Classroom' (Nunan, 1989) helped to set the agenda and to establish the language learning task as a pivotal component in design. Nunan's book dealt with the design and development of communicative language tasks and saw the task as "a basic planning tool" (1989: 1) and "the major focus of the teacher's planning efforts" (1989: 
134). It is noteworthy that the design of language learning tasks has remained firmly on the agenda to the present day. A good example in CALL is Salaberry's recent paper on the pedagogical design of CMC tasks (Salaberry, 2000).

Nunan provides a summary of the many definitions of a language learning 'task' (Nunan, 1989:5-6; see also Candlin, 1987; Breen, 1987). Nunan defines tasks in terms of, "their goals, the input data, linguistic or otherwise...the activities derived from the input, and the roles and settings for different tasks for teachers and learners." (1989:2). He also adds, importantly for our discussion here, that however well-designed and conceived the task, "we cannot know for certain how different learners are likely to carry out a task. We tend to assume that the way we look at a task will be the way learners look at it."(Nunan, 1989: 20; see also Breen, 1986). One way of dealing with this tendency is to involve learners in designing or selecting tasks and this point is taken up at length in Breen's paper, "Learner contributions to task design" (Breen, 1987). Among other things, the literature on tasks in the late 1980s illustrated some of the difficulties in reaching an agreed decision on a definition of task, the complexities of implementing a task that conforms to a design, and also the value of involving learners in task design.

As far as research on L2 classroom learning is concerned, tasks have also played a very productive role (Larsen-Freeman \& Long, 1991; Ellis, 1994:595). The main research goal related to tasks has been to discover how certain variables affect the interaction that occurs when learners attempt to perform a task (Ellis, 1994:595). The variables can be broadly classified into those that relate to the task and those that relate to the learner. There have been problems determining which variables to investigate and, as a result a 'task framework' has been suggested that can be used to 'classify and compare' different tasks. However, as in the examples above, definitions of task vary, and the term remains rather 'vague' (Ellis, 1994:595). At this stage, Ellis says, "Attempts to classify task variables in this way are helpful, but we are a long way from developing a taxonomy that is both complete and psychologically justified." (1994:596).

Returning to CALL, Meskill provides a "task anatomy for sociocollaborative language learning" based upon Cohen's notion of 'multiple ability tasks' which have the following qualities:

- Has more than one answer or more than one way to solve the problem;

- Is intrinsically interesting and rewarding;

- Allows different students to make different contributions;

- Uses multimedia;

- Involves sight, sound, and touch;

- Requires a variety of skills and behaviours;

- Also requires reading and writing;

- Is challenging. (Cohen, 1994:68)

This characterisation of task is different again from the ones given earlier, and illustrates how some of the multimedia elements available in the CALL domain might affect our understanding of task in this context.

A careful exploration of task in the teaching, learning and CALL contexts is worthy of a much more detailed examination than I have been able to give it here. However, it is clear that 'task' is a term that is open to many different interpretations. Definitions are 
being drawn, not only from the language teaching/learning domains, but also from education more broadly, and technology elements are clearly influencing particular realizations. Also, however well-theorised or designed the task may be, we do not know how the individual learner will perceive or respond to it. This is a crucial point, made by Hémard (1999), Goodfellow (1999) and others in CALL, and points to research that investigates learner perceptions more fully, and a much closer involvement by the user in the actual processes of task design from the outset. The learner's role is the focus in the next section.

\subsection{Focus on the learner}

To prepare a strong and workable design, it is imperative that the designer is sensitive to factors that emerge as a consequence of individual learner characteristics and the learning context. Ideally, designs would differ according to the conditions and parameters set by the learner and the learning context.

The problem for designs grounded in a specific theory of language learning or, for that matter, for commercially-produced materials aimed at the wider market, is the designer's lack of precise, detailed knowledge about the individual learner and the curricula and institutional context where the program will be used. Specific knowledge of the learner's age, sex, physical abilities, education, cultural or ethnic background, motivation, goals, and personality, computing experience and so on remain largely unknown. In these circumstances, the designer may rely on intelligent guesswork or traditional responses to design problems. Moreover, the designer often attempts to cover all the bases, and here Shneiderman's observation applies: "If implementers find that another command can be added, the designer is often tempted to include the command in the hope that some users will find it helpful." (Shneiderman, 1987:55). The audience remains remote to the author, at least in any detailed or specific sense, and generalised predictions have to be made; arguably, this is easier at beginner level than any other. There is no doubt that the better one knows the needs and characteristics of the user, the better one can make the design.

Wherever possible, to ensure that their needs are met, learners need to be involved in the design process. Learners can play an important role if they are given the opportunity. One of the many ways that this might occur was described by Crompton (1999), referred to earlier, in the development of a CALL grammar course (see Section 2.3.3).

An important feature in the design of Crompton's course in grammar for learners of Spanish was the Student Progress Log. Interestingly, even though the student's progress logs were carefully managed and maintained online, the students' insisted on 'handing in' a hard-copy of the Progress Log. Crompton speaks of the importance for students of "the ritual of handing something in' and, relatedly, the teaching and learning process as 'an extremely complex anthropological activity..." (1999:79) [italics in the original]. The students' need for a visible record of their progress prompted an unexpected move back to a hard copy Student Progress Log in Mark II of the Course. Another critical refinement came about as a result of recording the students' log-in times and scores in the exercises. Surprisingly, there was an inverse ratio between the length of the exercise and the amount of time spent completing it; in other words, the longer the exercise, the shorter the time the student was logged on to it, and vice-versa (1999:80). This appeared 
to be due to students leaving the exercise for a time and 'surfing' on the Internet: students visit other sites and then return later to the exercise. In this regard, Crompton (1999:80) makes some crucial points about design:

“...as well as short exercises there has to be a variety of activities within the units to keep the attention. The Internet is not electronic text; it is a much more exciting place, and any materials placed on it have to reflect that excitement, above all in the range and variety of activities offered. Just as no-one would think of producing a videotape consisting entirely of scrolled text, so the Internet has to match the professionalism and variety of other websites. It has to be interesting." [italics in the original]

These and other considerations drawn from student feedback and user monitoring led to a much refined model for version II. The refinements included (Crompton, 1999:81):

- Shorter exercises;

- A variety of hyperlinks with each exercise;

- Inclusion of realia to enable exercises with 'real' links;

- The whole module can be downloaded for home use;

- Discrete test;

- External accreditation.

Not surprisingly, Crompton concludes that the mark II version of the course is 'quite a different type of Internet activity' (Crompton, 1999:82).

\subsection{Designing through constraint}

In the earlier material in the category of design and state-of-the-art technology, problems of design were seen to be closely intertwined with an understanding of the precise limitations of the technology. As a result of these limitations certain trade-offs had to be made with the design. Once the technological constraints are known and understood the researcher or developer can proceed to establish how these facts might shape or ameliorate the pedagogical ambitions. With ASR, understanding its limitations is crucial for effective design. The designer can then work within the boundaries set. With this in mind, Wachowicz \& Scott (1999) give the wonderful example of a very clever interface in one ASR implementation. The interface appeared in the form of Traci who always appears a little absent-minded: what better way to cover for the current limitations in ASR technology than to use an interface that by its very persona forgets or does not understand the speaker first time around - and what better way to secretly encourage users to enunciate more clearly!

User needs, abilities and expectations may also function as a design constraint. This was evident in the discussion by Arneil and Holmes (1999) on the development of their 'Hot Potatoes' authoring system where they were endeavouring to meet the needs of different authors and their skill levels on a variety of browser platforms.

The point is that all new technology mediated systems have constraints of one kind or another. The trick is to understand very clearly exactly what they are, and the specific constraints they impose, and then to design effectively within these limitations. 


\section{Conclusion}

In closing, I would like to broaden out the discussion a little to focus on the role of the language teacher as designer. This is a very powerful concept and, surprisingly, it is a role that has not been examined extensively in the literature. ${ }^{4}$

Viewing the language teacher as a designer brings to the foreground some critical insights. The first and most important of these is that the language teacher in creating a product or plan of action operates within a set of interrelated constraints. Constraints, often associated with the limited time and resources available to the teacher and the student, typically include: the number of contact hours pre-determined for a course; lesson times and durations; preparation time; access to new technologies and to software; development budget; technical support; ancillary learning materials and so on. All of these constraints, in one way or another, directly impact on the ways in which a design is initially conceptualised and then brought to fruition, be it the design of a new CALL artifact of some kind, or the design of a classroom task using generic tools such as the word processor or email. ${ }^{5}$

The key factor in good design is to be able to identify and to understand the impact of authentic constraints and to be able to work creatively within them. To conceptualise language teaching or CALL without constraints and to assume 'ideal conditions' - as is so often the case with theoretically derived models of language teaching and learning is often to miss the point as far as successful design is concerned in real educational settings. Working without restrictions really does not teach very much. That is why the best pre-service and in-service professional development courses build authentic constraints into the tasks trainee language teachers are required to complete. Then, later, novice teachers will be in a much stronger position to operate within the constraints that will inevitably impinge on their work during their professional lives. It is only when the designer engages with the constraints that a deeper understanding of the true nature of the design problem becomes clear. If the idea of the teacher-designer is coupled with the idea of learner-designer there is even further opportunity for creative design in language teaching and learning.

\section{Acknowledgement}

I would particularly like to thank one of the anonymous reviewers for their comments on an earlier version of this paper.

\section{References}

Arneil, S. and Holmes, M. (1999) Juggling hot potatoes: decisions and compromises in creating authoring tools for the Web. ReCALL 11(2):12-19.

\footnotetext{
${ }^{4}$ The teacher as designer of language teaching materials is an exception, although this particular role is a more restricted application of the idea than the one advocated in the conclusion. It is also a role that can easily be forgotten when compared to the extensive references to the language teacher as facilitator or guide (see Richards \& Rodgers, 1986; Oxford et al., 1998).

${ }^{5}$ One of the roles of technology, of course, is to enable the removal or amelioration of certain constraints, the time available for teacher-student or student-student language learning opportunities, for example.
} 
Bangs, P. and Shield, L. (1999) Why change authors into programmers? ReCALL 11(1):19-29.

Bernstein, J., Najmi, A. and Ehsani, F. (1999) Subarashi: Encounters in Japanese spoken language education. CALICO Journal 16(3):361-384.

Blackburn, S. (1994) The Oxford Dictionary of Philosophy. Oxford: Oxford University Press.

Blake, R. (2000) Computer Mediated Communication: A window on L2 Spanish interlanguage. Language Learning and Technology 4(1):120-136.

Blake, R. J. (1999) Nuevos Destinos: A CD-ROM for advanced beginning Spanish. CALICO Journal 17(1):9-24.

Boling, E. and Soo, K. S. (1999) CALL issues: Designing CALL software. In: Egbert, J. and Hanson-Smith, E. (eds.), CALL Environments: Research, practice and critical issues, Alexandria: TESOL, 442-456.

Borchardt, F. L. (1999) Towards an aesthetics of multimedia. Computer Assisted Language Learning 12(1):3-28.

Boyle, T. (1997) Design for Multimedia Learning. London: Prentice Hall.

Breen, M. P. (1986) Learner contributions to task design. In: Candlin, C. and Murphy, D.F. (eds), Language Learning Tasks, London: Prentice-Hall, 23-46.

Breen, M.P., Candlin, C.N. and Waters, A. (1979) Communicative materials design: Some basic principles. RELC Journal 10(2):1-13.

Brett, P. (2000) Developing cross-cultural competence in business through multimedia courseware. ReCALL 12(2):196-208.

Brussino, G. (1999) Culture, communication, navigation and CALL: The role of the user interface and video material in a multimedia program for intermediate Italian learners. In: Cameron, $\mathrm{K}$. C. (ed.), CALL and the Learning Community, Exeter: Elm Bank Publications, 23-30.

Brussino, G., Luciano, B. and Gunn, C. (1999) Integrated CALL design: Crescendo in Italia, a language teaching package for intermediate Italian learners. Computer Assisted Language Learning 12(5):409-426.

Buckett, J., Stringer, G. and Data, N. J. K. (1999) Life after ReLaTe: Internet videoconferencing's growing pains. In: Cameron, K. C. (ed.), CALL and the Learning Community, op. cit., 31-38.

CALL Cookbook: http://www.owlnet.rice.edu/ ling417/

Cameron, K. C. (ed.) (1999a) CALL: Media, Design and Applications. Lisse: Swets and Zeitlinger.

Cameron, K. C. (ed.) (1999b) CALL and the Learning Community. Exeter: Elm Bank Publications.

Candlin, C. N. and Murphy, D. F. (1986) Language Learning Tasks. Lancaster Practical Papers in English Language Education. Volume 7. London: Prentice-Hall International.

Candlin, C. N. (1987) Towards task-based learning. In: Candlin, C. and Murphy, D. (eds.), op. cit., 5-22.

Chapelle, C. (1997) CALL in the year 2000: still in search of research paradigms? Language Learning and Technology 1(1):19-43.

Chapelle, C. (1998) Multimedia CALL: lessons to be learned from research on instructed SLA. Language Learning and Technology 2(1):22-34.

Chapelle, C. (1999) Theory and research: Investigation of 'authentic' language learning tasks. In: Egbert, J. and Hanson-Smith, E. (eds.) op. cit., 101-115.

Chapelle, C. (2000) Is network-based learning CALL? In: Warschauer, M. and Kern, R. (eds.), Network-based Language Teaching: Concepts and practice, Cambridge: Cambridge University Press, 204-228.

Chapelle, C. (2001) Computer Applications in Second Language Acquisition: Foundations for teaching, testing and research. Cambridge: Cambridge University Press.

Chen, H. (1999) Creating a virtual language lab: An EFL experience at National Taiwan Ocean University. ReCALL 11(2). 
Chun, D. M. and Plass, J. L. (2000) Networked multimedia environments for second language acquisition. In: Warschauer, M. and Kern, R. (eds.), op. cit., 151-170.

Clark, C. M. (1992) Teachers as designers in self-directed professional development. In: Hargreaves, A. and Fullan, M. G. (eds.) Understanding Teacher Development New York: Teachers College Press, 75-109.

Coyne, R. (1997) Designing Information Technology in the Information Age: From method to metaphor. Cambridge, Mass.: MIT Press.

Crompton, P. M. (1999) Integrating Internet-based CALL materials into mainstream language teaching. In: Cameron, K. (ed.), CALL and the Learning Community, op. cit., 75-82.

Crozet, C. and Liddicoat, A. J. (1997) Teaching culture as an integrated part of language teaching: An introduction. Teaching Languages, Teaching Culture. Australian Review of Applied Linguistics. Series S, Number 14: 1-22.

Curtis, S. A., Duchasel, J. and Radic, N. (1999) Proposal for an online language course. ReCALL 11(2):38-45.

Dalby, J. and D. Kewley-Port (1999) Explicit pronunciation training using automatic speech recognition. CALICO Journal 16(3):425-446.

Dave's ESL Café: http://www.pacificnet.net/ sperling/eslcafe.html

De Ridder, I. (1999) Are we still reading or just following links? How the highlighting or hyperlinks can influence incidental vocabulary learning. In: Cameron, K.C. (ed.), CALL and the Learning Community, op. cit., 105-116.

De Ridder, I. (2000) Are we conditioned to follow links? Highlights in CALL materials and their impact on the reading process. Computer Assisted Language Learning 13(2):183-195.

Debski, R. (2000) Exploring the re-creation of a CALL innovation. Computer Assisted Language Learning 13(4-5):307-332.

Debski, R. and Gruba, P. (1999) A qualitative survey of tertiary instructor attitudes towards project-based CALL. Computer Assisted Language Learning 12(3):219-239.

Debski, R. and Levy, M. (eds.) (1999) WORLDCALL: Global Perspectives on Computer-Assisted Language Learning, Lisse: Swets and Zeitlinger.

Dias, J. (1999). Initiating learner autonomy with CALL. In: Cameron, K. C. (ed.), CALL and the Learning Community, op. cit., 117-126.

Egbert, J. and Hanson-Smith, E. (eds.) (1999) CALL Environments: Research, Practice and Critical Issues, Alexandria: TESOL.

Ellis, R. (1994) The Study of Second Language Acquisition. Oxford: Oxford University Press.

Ellis, R. (1997) SLA Research and Language Teaching. Oxford: Oxford University Press.

Fischer, R. and Farris, M. (1999). The Libra multimedia authoring environment and CALL multimedia courseware. CALICO Journal 17(1):59-82.

Fischer, R. (1999) Computer applications and research agendas: another dimension in professional advancement. CALICO Journal 16(4):559-571.

Frommer, J. and Foelsche, O. K. E. (1999) SuperMacLang: Development of an authoring system. CALICO Journal 17(1):115-141.

Garrett, N. (1990) Forward. In: Dunkel, P. (ed.), Computer-Assisted Language Learning and Testing: Research Issues and Practice, New York: Newbury House, xii-xvi.

Garrett, N. (1998) Where do research and practice meet? Developing a discipline. ReCALL 10(1):7-12.

Goodfellow, R. (1999) Evaluating performance, approach and outcome. In: Cameron, K. C. (ed.), CALL: Media, design and applications, op. cit., 109-140.

Goodfellow, R., Manning, P. and Lamy, M.-N. (1999) Building an online open and distance language learning environment. In: Debski, R. and Levy, M. (eds.), WORLDCALL, op. cit., 267-286.

Greaves, C. and Yang, H. (1999) A vocabulary-based language learning strategy for the Internet. In: Debski, R. and Levy, M. (eds.), WORLDCALL, op. cit., 67-84. 
Hamburger, H., Schoelles, M. and Reeder, F. (1999) More intelligent CALL. In: Cameron, K. (ed.), CALL: Media, Design and Applications, op. cit., 183-202.

Harben, P. (1999). An exercise in applying pedagogical principles to multimedia CALL materials design. ReCALL 11(3):25-33.

Harless, W. C., Zier, M. A. and Duncan, R. C. (1999) Virtual dialogues with native speakers: the evaluation of an interactive multimedia method. CALICO Journal 16(3):313-338.

Harrington, M. and Levy, M. (2001) CALL begins with a 'C': Interaction in computer-mediated language learning. System 29(1):15-26.

Hémard, D. (1999) A methodology for designing student-centred hypermedia CALL. In: Debski, R. and Levy, M. (eds.), WORLDCALL, op. cit., 215-228.

Hémard, D. and Cushion, S. (1999) Designing a web-based CALL environment: From access to acceptability. In: Cameron, K.C. (ed.) CALL and the Learning Community, op. cit., 169-180.

Herring, S. (ed.) (1996) Computer-Mediated Communication: Linguistic, Social and CrossCultural Perspectives. Amsterdam: John Benjamins.

Hewer, S., Kotter, M., Rodine, C. and Shield, L. (1999) Criteria for the selection of on-line tools for fluency-oriented tasks for distance language learners. CAL 99: Virtuality in Education.

Hickman, L. A. (1992) John Dewey's Pragmatic Technology. Bloomington: Indiana University Press.

Holland, M. (1999) Tutors that listen. Special Issue. CALICO Journal 16(3):245-250.

Holland, V. M., Kaplan, J. D. and Sams, M. R. (eds.) (1995) Intelligent Language Tutors: Theory Shaping Technology. Lawrence Erlbaum, Mahwah, New Jersey.

Holland, M., Kaplan, J. D. and Sabol, M. A. (1999) Preliminary tests of language learning in a speech-interactive graphics microworld. CALICO Journal 16(3):339-360.

Hoven, D. (1999a) A model for listening and viewing comprehension in multimedia environments. Language Learning and Technology 3(1):88-103.

Hoven, D. (1999b) CALL-ing the learner into focus: Towards a learner-centred model. In: Debski, R. and Levy, M. (eds.), WORLDCALL, op. cit., 149-168.

Hubbard, P. (1992) A methodological framework for CALL courseware development. In: Pennington, M. C. and Stevens, V. (eds.), Computers in Applied Linguistics. Clevedon: Multilingual Matters, 39-65.

Jacobson, M. (1994) Issues in Hypertext and Hypermedia Research: Toward a Framework for Linking Theory-to-Design. Journal of Educational Multimedia and Hypermedia 3(2):141-154.

Jones, C. (1999a) Language Courseware Design. Special Issue. CALICO Journal 17(1).

Jones, C. (1999b) Contextualise and personalise: Key strategies for vocabulary acquisition. $\operatorname{ReCALL~11(3):34-40.~}$

Jones, C. M. and Frommer, J. (1999). Building the Portes Ouvertes CD-ROM. CALICO Journal 17(1):83-100.

Kern, R. and Warschauer, M. (2000) Introduction: Theory and practice of network-based language teaching. In: Warschauer, M. and Kern, R.(eds.), op. cit, pp.1-19.

Kitade, K. (2000) L2 learners' discourse and SLA theories in CMC: Collaborative interaction in Internet chat. Computer Assisted Language Learning 13(1):143-166.

Klassen, J. and Milton, P. (1999) Enhancing English language skills using multimedia: tried and tested. Computer Assisted Language Learning 12(4):281-294.

Koet, T. (1999) ICT and language skills: an integrated course. ReCALL 11(1):65-71.

Kötter, M., Shield, L. and Stevens, A. (1999) Real-time audio and email for fluency: promoting distance language learners' aural and oral skills via the Internet. ReCALL 11(2):55-60.

Lamy, M.-N. and Goodfellow, R. (1999) 'Reflective conversation' in the virtual language classroom. Language Learning and Technology 2(2):43_61.

Leahy, C. (1999) Email as a learning tool: Construction of knowledge online. In: Cameron, K. (ed.), CALL and the Learning Community, op. cit., 291-300.

Levine, A., Ferenz, O. and Reves, T. (1999). A computer mediated curriculum in the EFL aca- 
demic writing class. ReCALL 11(1):72-79.

Levy, M. (1997) Computer-Assisted Language Learning: Context and Conceptualisation, Oxford: Clarendon Press.

Levy, M. (1999a) Theory and design in a multimedia CALL project in cross-cultural pragmatics. Computer Assisted Language Learning 12(1):29-58.

Levy, M. (1999b) Design processes in CALL: integrating theory, research and evaluation. In Cameron, K. C. (ed.), CALL: Media, design and applications, op. cit., 83-108.

Levy, M. (2000) Scope, goals and methods in CALL research: Questions of coherence and autonomy. ReCALL 12(2):170-195.

Larsen-Freeman, D. and Long, M. H. (1991) An Introduction to Second Language Acquisition Research. New York: Longman.

Liddicoat, A. J. and Crozet, C. (eds.) (1997) Teaching Languages, Teaching Culture. Australian Review of Applied Linguistics. Series S, Number 14.

LinguaCentre Grammar Safari: http://deil.lang.uiuc.edu/web.pages/grammarsafari.html

Mak, L. and Yeung, S. (1999) Investigating features of an international email community. In: Cameron, K.C. (ed.), CALL and the Learning Community, op. cit., 315-336.

Meskill, C. (1999) Computers as tools for sociocollaborative language learning. In: Cameron, K. (ed.), CALL: Media, design and applications, op. cit., 141-164.

Mills, D. (1999) Interactive web-based language learning: The state of the art. In: Debski, R. and Levy, M. (eds.), WORLDCALL, op. cit., 117-132.

Mills, J. (1999). CA-EAP: A multitask software package for the teaching of academic writing. In: Cameron, K.C. (ed.), CALL and the Learning Community, op. cit., 345-354.

Mitchell, R. and Myles, F. (1998) Second Language Learning Theories. London: Arnold.

Mostow, J. and Aist, G. (1999) Giving help and praise in a reading tutor with imperfect listening. CALICO Journal 16(3):407-424.

Mugane, J. (1999) Digital arenas in the delivery of African languages for the development of thought. In: Debski, R. and Levy, M. (eds.), WORLDCALL, op. cit., 33-48.

Murray, G. L. (1999a) Exploring learners' CALL experiences: a reflection on method. Computer Assisted Language Learning 12(3):179-195.

Murray, G. L. (1999b) Autonomy and language learning in a simulated environment. System 27(3):295-308.

Negretti, R. (1999) Web-based activities and SLA: a conversation analysis research approach. Language Learning and Technology 3(1):75-87.

Nelson, T. and Oliver, W. (1999) Murder on the Internet. CALICO Journal 17(1):101-114.

Nunan, D. (1989) Designing Tasks for the Communicative Classroom. Cambridge: Cambridge University Press.

Ohlsson, S. (1993) Impact of Cognitive Theory on the Practice of Courseware Authoring. Journal of Computer Assisted Learning 9:194-221.

Orsini-Jones, M. (1999) Implementing institutional change for languages: Online collaborative learning environments at Coventry University. ReCALL 11(2):61-73.

Oxford, R. L., Tomlinson, S., Barcelos, A. Harrington, C., Lavine, R., Saleh, A. and Longhini, A. (1998) Clashing metaphors about classroom teachers: Toward a systematic typology for the language teaching field. System 26:3-50.

Paramskas, D. M. (1999) The shape of computer-mediated communication. In: Cameron, K.C. (ed.), CALL: Media, Design and Applications, op. cit., 13-34.

Pellettieri, J. (2000) Negotiation in cyberspace: The role of chatting in the development of grammatical competence. In: Warschauer, M. and Kern, R. (eds.), op. cit., 59-86.

Peterson, M. (1999) Creating hypermedia learning environments: Some guidelines for learnercentred design. In: Cameron, K. (ed.), CALL and the Learning Community, op. cit., 363-368.

Pica, T. and Doughty, C. (1985) The role of group work in classroom second language acquisition. 
Studies in Second Language Acquisition, 7: 233-48.

Price, C., McCalla, G. and Bunt, A. (1999) L2tutor: A mixed-initiative dialogue system for improving fluency. Computer Assisted Language Learning 12(2):83-112.

Pusack, J. P. (1999) The Kontakte multimedia project at the University of Iowa. CALICO Journal 17(1):25-42.

Richards, J. C. and Rodgers, T. S. (1986) Approaches and Methods in Language Learning. Cambridge: Cambridge University Press.

Richey, A. (1998) The pursuit of useable knowledge in Instructional technology. Educational Technology, Research and Development 46(4):7-21.

Robb, T. N. and Susser, B. (2000) The life and death of software: Examining the selection process. CALICO Journal 18(1):41-52.

Salaberry, R. (1999) CALL in the year 2000: Still developing the research agenda. A commentary on Carol Chapelle's CALL in the year 2000: Still in search of research paradigms? Language Learning and Technology, 3(1), 104-107.

Salaberry, R. (2000) Pedagogical design of computer mediated communication tasks: Learning objectives and technological capabilities. The Modern Language Journal 84(1):28-37.

Shield, L. and Hewer, S. (1999) A synchronous learning environment to support distance language learners. In: Cameron, K. C. (ed.), CALL and the Learning Community, op. cit., 379-390.

Shield, L. and Weininger, M. J. (1999) Collaboration in a virtual world: Groupwork and the distance language learner. In: Debski, R. and Levy, M. (eds.), WORLDCALL, op. cit., 99-116.

Shield, L., Weininger, M. J. and Davies, L. B. (1999). A task-based approach to using MOO for collaborative language learning. In: Cameron, K. C. (ed.), CALL and the Learning Community, op. cit., 391-402.

Shneiderman, B. (1987) Designing the User Interface: Strategies for effective human-computer interaction. Reading, Mass.: Addison-Wesley.

Sivert, S. and J. Egbert (1999) CALL issues: Building a computer-enhanced language classroom. In: Egbert, J. and Hanson-Smith, E. (eds.), op. cit., 41-49.

Söntgens, K. (1999) Language learning via email - autonomy through collaboration. In: Cameron, K. C. (ed.), CALL and the Learning Community, op. cit., 413-424.

Sotillo, S. M. (2000) Discourse functions and syntactic complexity in synchronous and asynchronous communication. Language Learning and Technology 4(1):82-119.

Stockwell, G. and Levy, M. (2001) Sustainability of email interactions between native speakers and nonnative speakers. Computer Assisted Language Learning 14(5):419-442.

Tchaïcha, J. D. (1999) Technology and the second language learner: how does it work best? In: Debski, R. and Levy, M. (eds.), WORLDCALL, op. cit., 287-302.

Tomlinson, B. (ed.) (1998) Materials Development in Language Teaching. Cambridge: Cambridge University Press.

Truscott, J. (1998) Noticing in second language acquisition: A critical review. Second Language Research, 14(2), 103-135.

Tschichold, C. (1999) Grammar checking for CALL: Strategies for improving foreign language grammar checkers. In: Cameron, K.C. (ed.), CALL: Media, design and applications, op. cit., 203-222.

Van Aacken, S. (1999) What motivates L2 learners in acquisition of Kanji using CALL? Computer Assisted Language Learning, 12(2): 113-136.

Vanparys, J. and Baten, L. (1999) How to offer real help to grammar learners. ReCALL 11(1):125-132.

VCU Trail Guide: http://www.fln.vcu.edu/default.html

Wachowicz, K. and Scott, B. (1999) Software that listens: it's not a question of whether, it's a question of how. CALICO Journal 6(3):253-276.

Warschauer, M. and Kern, R. (eds.), Network-based language teaching: Concepts and practice. 
Cambridge: Cambridge University Press.

Whistle, J. (1999a) Concordancing and learner autonomy: An experiment with first and second year undergraduates. In: Cameron, K.C. (ed.), CALL and the Learning Community, op. cit., 443-454.

Whistle, J. (1999b) Concordancing with students using an 'off-the-Web' corpus. ReCALL 11(2).

Winograd and Flores (1986) Understanding Computers and Cognition. Reading, Mass.: AddisonWesley.

Wong, J. and Fauverge, A. (1999) LEVERAGE - Reciprocal peer tutoring over broadband networks. ReCALL 11(1):133-142.

Zähner, C., Fauverge, A. and Wong, J. (2000) Task-based language learning via audiovisual networks: The LEVERAGE project. In: Warschauer, M. and Kern, R. (eds.), op. cit., 186-203.

\section{Appendix A: Identifiers or 'candidate' descriptors'}

\section{DESIGN}

Scope notes: Design is an important focus in the article. Details are given in each category below. This design focus may be expressed in a number of ways and at a number of levels. It includes:

- Design as a general, principled approach to CALL (when PRINCIPLE will also appear) This is used for discussion of design at a higher level of abstraction and includes:

- $\quad$ a 'paradigm', 'model' or 'theory' of CALL relating directly to design, most especially the design of CALL tasks (e.g. Hoven, 1999)

- broad approaches to conceptualizing design (e.g. Levy, 1999; Borchardt, 1999)

a design methodology (e.g. Hemard, 1999)

- $\quad$ guidelines or software design principles (e.g. Boling and Soo,1999; Peterson, 1999)

- Design of a particular artifact (when ARTIFACT will also appear). CALL artifacts include:

- $\quad$ websites (e.g. Mugane, 1999)

- $\quad$ learning environments (e.g. Goodfellow, Manning and Lamy, 1999)

- $\quad$ courseware packages (e.g. Pusack, 1999)

- $\quad$ exercises (e.g. Harben, 1999)

- $\quad$ authoring systems (e.g. Arneil and Holmes, 1999)

- $\quad$ Design of CALL materials sharing a 'state-of-the-art' technological feature (when TECHNOLOGY and the feature, e.g. 'speech_recognition', will also appear). This includes:

- $\quad$ speech recognition (e.g. Wachowicz and Scott, 1999)

- $\quad$ broadband video conferencing (e.g. Wong and Fauverge, 1999)

- Design of an online course (when COURSE will also appear, e.g. Curtis et al.,1999)

- Design as it relates to other aspects of CALL. This includes:

- $\quad$ computer or classroom laboratories (e.g. Sivert and Egbert, 1999)

- $\quad$ ICALL (e.g. Hamburger, Schoelles and Reeder, 1999)

- $\quad$ corpus-based work (e.g. Whistle, 1999)

- $\quad$ grammar checkers (e.g. Tschichold, 1999)

${ }_{6}$ Descriptors given in Levy (2000) are not repeated. 
Compatible: ARTIFACT, CMC

Not compatible: RATIONALE $\rightarrow$ APPL'N

Note: 1. PRINCIPLE is only used with DESIGN and is defined above

2. The identifier 'Design' is NOT used in the sense of the design of a research study.

\section{AUTHORING}

Scope notes: Authoring CALL materials is discussed

Authoring may be considered in a general way, for example the teacher's role in authoring CALL materials, or specific authoring tools (in-house or commercially-produced) are described, compared and/or evaluated in depth (e.g. Mills, D., 1999). Authoring tools includes all programs used to develop CALL materials including multimedia and Web-based authoring tools (e.g. ToolBook, FrontPage, DreamWeaver, WebCT). Implications for the potential user in terms of learning difficulty, for example, are also often covered (e.g. Bickerton, 1999).

\section{EVALUATION}

Scope notes: An aspect of CALL is evaluated in a detailed or specific way.

Examples include Wachowicz and Scott (1999) on speech recognition, or Mills, D. (1999) and Godwin-Jones (1999) evaluating different Web-authoring options. This keyword includes evaluation in terms of effectiveness research (e.g. Pellerin, 1999), evaluation of research methods (e.g. Murray, 1999) and, more informally, reports on strengths and weaknesses including: Paramskas (1999) for CMC; Dawson (1999) for CALL and Communicative Language Teaching; and Haworth and Cowling (1999) for the Web-Enhanced Language Learning Project. It is not used in the sense of evaluation of student's work (e.g. Nishinoh, 1999).

\section{TECHNOLOGY}

Scope notes: A state-of-the-art technology is a major focus in the article

The discussion centres upon a specific technology (e.g. speech recognition) rather than a specific artifact, though the artifact may be used as an example of the technology. An evaluation of the technology will usually be included. Specific examples of the use of this descriptor are: e.g. LEVERAGE (Wong and Fauverge, 1999); the CALICO ASR papers; the ReLaTe video conferencing project (Buckett et al., 1999); AI dialogue generation (Price et al., 1999)

Compatible: DESIGN, EVALUATION, ARTIFACT

Not compatible: PRACTICE

\section{THEORY}

Scope notes: There is a specific reference to a theory or theories, especially as a framework or guide for design (e.g. Blin, F., 1999)

Compatible: RESEARCH_DISCUSS, RATIONALE $\rightarrow$ APP'N, ARTIFACT, DESIGN

Not compatible: PRACTICE 